\title{
SYNTHESIS AND CHARACTERIZATION OF THE LAMELLAR OXYCHLORIDE $\mathrm{CO}_{2} \mathrm{CU}_{4} \mathrm{TE}_{4} \mathrm{O}_{11} \mathrm{CL}_{4}$
}

\author{
D. RUIZ - LEÓN*AND. E. SPODINE
}

Universidad de Chile, Facultad de Ciencias Químicas y Farmacéuticas, Departamento de Química Inorgánica y Analítica, Casilla 233, Santiago, Chile Centro para la Investigación Interdisciplinaria Avanzada en Ciencias de los Materiales (CIMAT)

Universidad de Chile

(Received: 7 December 2007 - Accepted: 9 April 2008)

\begin{abstract}
In this work we describe the synthesis and characterization of the $\mathrm{Co}_{2} \mathrm{Cu}_{4} \mathrm{Te}_{4} \mathrm{O}_{11} \mathrm{Cl}_{4}$ phase prepared by the hydrothermal technique. From the polycrystalline $\mathrm{X}$-ray diffraction pattern the obtained new phase was indexed in the P-1 space group with cell parameters $\mathbf{a}=9.274(7), \mathbf{b}=12.132(2), \mathbf{c}=9.252(2) \AA, \alpha=$ 98.18(14), $\beta=108.22(13)$ and $\gamma=111.07(8)^{\circ}$. The nominal composition and morphology were obtained using SEM-EDX measurements. The optical band gap of the material corresponds to an insulating system with $2.7 \mathrm{eV}$, and the thermogravimetric data shows that the phase is stable up to $700{ }^{\circ} \mathrm{C}$.
\end{abstract}

\section{INTRODUCTION}

From the synthetic point of view, the hydrothermal synthesis is referred to the preparation of substances in sealed containers, heated up at above room temperature and autogenerated pressures. An interesting fact of this synthesis is that it enables working at non thermodynamic conditions permitting the crystallization of compounds with different structures due to the variation of the physicochemical properties of the solutions. Basically, the mechanism of the hydrothermal reactions obeys a model of liquid nucleation ${ }^{1}$ which differs from the synthesis in solid state where the mechanism of reaction consists basically in the diffusion of atoms and ions in the interphase between the reactants. This method has been used in the synthesis of interesting types of solid phases like microporous crystals, super-ionic conductors, and chemical sensors, electronic and magnetic solids ${ }^{2-6}$.

Between current techniques used for the production of nanostructured materials, the hydrothermal synthesis presents many benefits, high degree of chemical homogeneity at molecular scale, the use of low temperatures as compared with solid state syntheses, formation of nanocrystalline materials in a one-step process. Nowadays, the hydrothermal technique represents the most promising route for the cost-reducing production of advanced ceramic materials like polycrystalline oxides, electroceramics, hybrid organic- inorganic materials and molecular systems with transition metals with characteristics adapted to technological applications.

An interesting family of compounds that presents an increasing development during the last years corresponds to the oxychlorides of transition metals, which are phases of great interest due to their intercalation properties, superconducting properties at high temperature, electric, optical and magnetic properties $^{7-13}$. For example, a wide range of amines have been intercalated in $\mathrm{FeOCl}, \mathrm{TiOCl}, \mathrm{VOCl}$ and $\mathrm{LnOCl}(\mathrm{Ln}=\mathrm{Ho}, \mathrm{Er}, \mathrm{Tm} \text { and } \mathrm{Yb})^{7-9}$. On the other hand, phases like $(\mathrm{Ca}, \mathrm{Na})_{2} \mathrm{CuO}_{2} \mathrm{Cl}_{2}$ and $(\mathrm{Ca}, \mathrm{Na})_{2} \mathrm{CaCu}_{2} \mathrm{O}_{4} \mathrm{Cl}_{2}$ have proven to be materials with a high Curie temperature ${ }^{14-15}$. The phase $\mathrm{Ba}_{5} \mathrm{Co}_{5} \mathrm{ClO}_{3}$ shows both antiferromagnetic and ferromagnetic phenomena ${ }^{16}$, while $\mathrm{Sr}_{2} \mathrm{MnO}_{3} \mathrm{Cl}$ and $\mathrm{Sr}_{4} \mathrm{Mn}_{3} \mathrm{O}_{8}$ are compounds with strong antiferromagnetic interactions ${ }^{17}$. On the other hand $\mathrm{Bi}_{3} \mathrm{~Pb}_{2} \mathrm{Nb}_{2} \mathrm{O}_{11} \mathrm{Cl}$ presents ferroelectricity ${ }^{18}$ and the phase $\mathrm{BiSeO}_{3} \mathrm{Cl}$ is active in the generation of a second harmonic ${ }^{12}$, which is fundamental in nonlinear optics.

In addition, recently Okamoto's group ${ }^{19}$ has started to work on a new oxychloride family of rare earths doped with calcium, which are promising solid state conductive electrolytes. This effect is due to the migration of chloride ions across the inorganic framework. Due to the interesting and peculiar characteristics to being insoluble in water and very stable at high temperatures, they are potential candidates to be $\mathrm{HCl}$ or $\mathrm{Cl}_{2}$ sensors. This type of phases have been synthesized both by ceramic, hydrothermal methods and vapor transporting reactions ${ }^{20-22}$.

In this context, telurites are particularly interesting not only from a structural point of view, since they can adopt a varied number of coordination environments, but also due to their the magnetic behavior. Despite the fact that these structures present the usual $\mathrm{TeO}_{3}^{-2}$ pyramidal fragment, which is quite common in sulfites and selenites ${ }^{23}$, telurites ${ }^{24}$ can also show a tetracoordinated fragment $\mathrm{TeO}_{4}^{-4}$ with a $\mathrm{C}_{22}$ symmetry, and can adopt a unique geometry of the type $\mathrm{TeO}_{3+1}^{-4}$, where one of the axial positions of the pseudotrigonal bipyramid is longer than the other ones ${ }^{25}$. This unusual and rich chemistry, has given a renewal interest to the production of new telurites phases like the spiroffite structure $\mathrm{M}_{2} \mathrm{Te}_{3} \mathrm{O}_{8}(\mathrm{M}=\mathrm{Co}, \mathrm{Cu}, \mathrm{Zn})^{26}$.
New works on oxychlorides of tellurium and copper with other transition metals do not exist in literature. Due to this fact, the aim of this work was to prepare and characterize new phases derived from oxychlorides.

\section{EXPERIMENTAL}

Polycrystalline phase $\mathrm{Co}_{2} \mathrm{Cu}_{4} \mathrm{Te}_{4} \mathrm{O}_{11} \mathrm{Cl}_{4}$, was synthesized using the hydrothermal method. Solid reagents, $\mathrm{CoCl}_{2}, \mathrm{CuO}, \mathrm{TeO}_{2}$, in a relation 1:2:2 were weighted in stoichiometric amounts and placed within the reactor. The autoclave bomb was loaded with $2 \mathrm{ml}$ of aqueous $5 \mathrm{M} \mathrm{NH}_{4} \mathrm{Cl}$ solution used as mineralizing agent. The hydrothermal bomb was placed in a furnace and then heated to $375^{\circ} \mathrm{C}$ for a period of 5 days. The obtained material was filtered and washed with $\mathrm{H}_{2} \mathrm{O}$, methanol and acetone.

The elementary analysis and morphology of the sample were obtained from SEM-EDX measurements.

Room temperature diffuse reflectance measurements from 800 to $200 \mathrm{~nm}$ were made using a Perking Elmer spectrophotometer. Barium sulfate was used as the reflectance standard. The reflectance data was converted to absorbance data using the Kubelka-Munk function.

Thermogravimetric measurements were carried out in order to get information about the thermal stability of the sample.

Powder diffraction data were obtained using a Siemens D-5000 diffractometer, equipped with monochromated $\mathrm{Cu} K$ radiation $(\lambda=1.54056$ $\AA$ ). The lattice parameters were obtained using a minimum of 29 lines from $2 \theta=5-60^{\circ}$. For the phase analysis a STOE equipment with a molybdenum source equipped with monochromated Mo $K_{\alpha}$ radiation $(\lambda=0.70930 \AA)$ and linear PSD detector in transmission scan mode was used to decrease the high fluorescence observed in the background of the measured samples.

\section{RESULTS AND DISCUSSION}

Several reactions with different stoichiometric ratios and different temperatures were carried out, in order to obtain the optimal conditions for a high purity phase. For example at $250^{\circ} \mathrm{C}$, if the ratio of $\mathrm{CoCl}_{2}, \mathrm{CuO}, \mathrm{TeO}_{2}$ is 1:2:2 the principal product is the $\mathrm{Co}_{2} \mathrm{Te}_{3} \mathrm{O}_{8}$ (Figure 1a) (spiroffite structure), while changing the ratios to $1: 2: 4$, the principal products are the $\mathrm{Co}_{2} \mathrm{Te}_{3} \mathrm{O}_{8}$ phase and the $\mathrm{TeO}_{2}$ (Figure 1b). Stoichiometric relations between the reagents $\mathrm{CoCl}_{2}, \mathrm{CuO}, \mathrm{TeO}_{2}$, in a ratio 1:2:2 was found to be the optimal, at the reaction temperature of $375^{\circ} \mathrm{C}$. The results are summarized in table 1. 

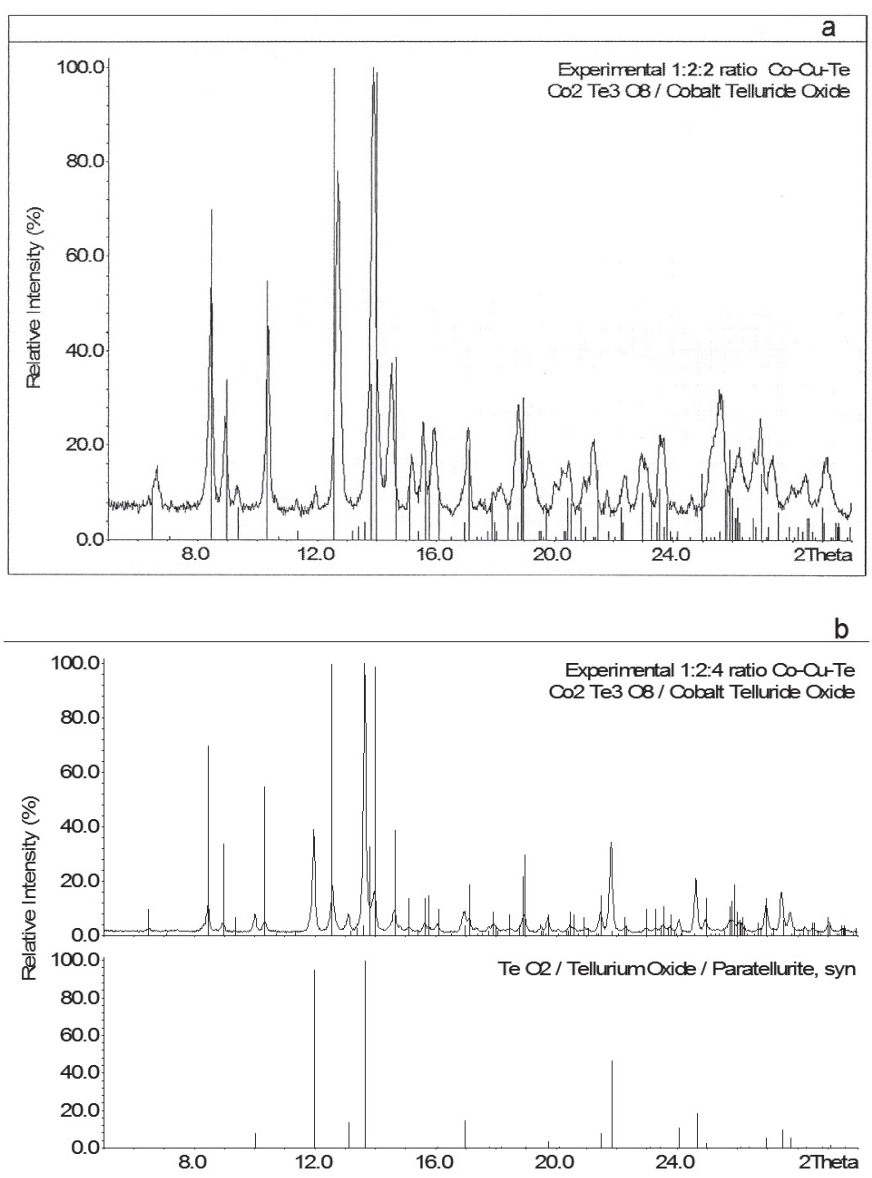

Figure 1. Powder X-ray diffraction patterns at different $\mathrm{CoCl}_{2}, \mathrm{CuO}, \mathrm{TeO}_{2}$ ratios a) 1:2:2 b) 1:2:4

Table 1. Obtained products at different ratios and temperatures for the $\mathrm{Co}_{2} \mathrm{Cu}_{4} \mathrm{Te}_{4} \mathrm{O}_{11} \mathrm{Cl}_{4}$ synthesis.

\begin{tabular}{|c|c|c|c|c|}
\hline \multicolumn{3}{|c|}{ Molar ratios } & \multirow{2}{*}{$\begin{array}{c}\text { Temperature } \\
\left({ }^{\circ} \mathrm{C}\right)\end{array}$} & Observed products \\
\cline { 1 - 2 } $\mathrm{CoCl}_{2}$ & $\mathbf{C u O}$ & $\mathrm{TeO}_{2}$ & & \\
\hline 1 & 2 & 2 & 250 & $\mathrm{Co}_{2} \mathrm{Te}_{3} \mathrm{O}_{8}$ \\
\hline 1 & 2 & 4 & 250 & $\mathrm{Co}_{2} \mathrm{Te}_{3} \mathrm{O}_{8}$ and $\mathrm{TeO}_{2}$ \\
\hline 1 & 2 & 2 & 375 & $\mathrm{Co}_{2} \mathrm{Cu}_{4} \mathbf{T e}_{4} \mathbf{O}_{11} \mathbf{C l}_{4}$ \\
\hline 1 & 2 & 4 & 375 & $\mathrm{Co}_{2} \mathrm{Te}_{3} \mathrm{O}_{8}$ and $\mathrm{TeO}_{2}$ \\
\hline
\end{tabular}

Chemical composition was determined using SEM-EDX. The secondary and retro-dispersed electrons confirm the stoichiometry and the homogeneity of the sample. The nominal composition was found to be $\mathrm{Co}_{24} \mathrm{Cu}_{3.8} \mathrm{Te}_{42} \mathrm{O}_{105} \mathrm{Cl}_{43}$ (Table 2).The morphology of the obtained phase is shown in the micrograph given in Figure 2. EDX

Table 2. Atomic percent for the $\mathrm{Co}_{2} \mathrm{Cu}_{4} \mathrm{Te}_{4} \mathrm{O}_{11} \mathrm{Cl}_{4}$ phase obtained from

\begin{tabular}{|l|c|c|c|c|c|}
\hline Atom \% & Te & Cu & Co & Cl & O \\
\hline Theoretical & 16.0 & 16.0 & 8.0 & 16.0 & 44.0 \\
\hline Experimental & 16.6 & 15.2 & 9.5 & 17.1 & 41.6 \\
\hline
\end{tabular}

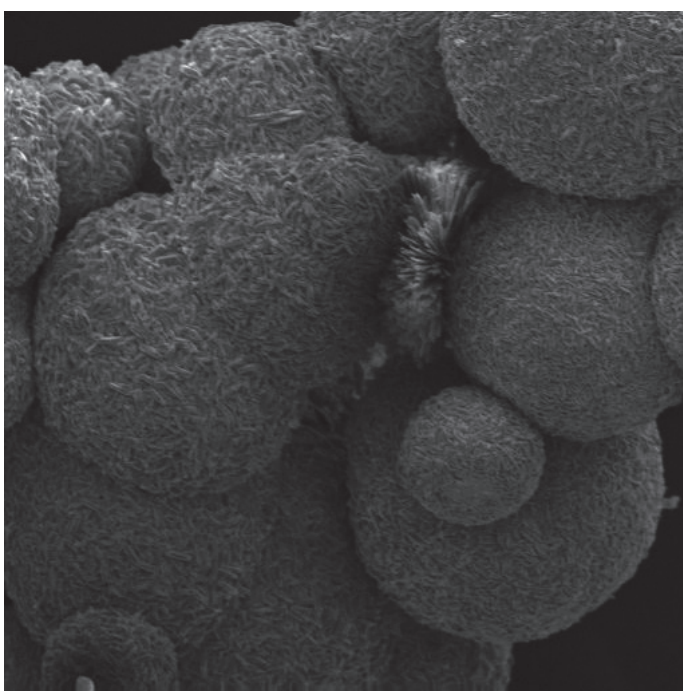

Figure 2. SEM image showing the morphology of the $\mathrm{Co}_{2} \mathrm{Cu}_{4} \mathrm{Te}_{4} \mathrm{O}_{11} \mathrm{Cl}_{4}$ phase

For $\mathrm{Co}_{2} \mathrm{Cu}_{4} \mathrm{Te}_{4} \mathrm{O}_{11} \mathrm{Cl}_{4}$ the lattice parameters were obtained indexing the sample from powder diffraction data in the space group $\mathrm{P}-1$ with cell parameters of $\mathbf{a}=9.274(7), \mathbf{b}=12.132(2), \mathbf{c}=9.252(2) \AA, \alpha=98.18, \beta=108.22$ and $\gamma=$ $111.07^{\circ}$, which are related to the isoestructural compound $\mathrm{Ba}_{2} \mathrm{Cu}_{4} \mathrm{Te}_{4} \mathrm{O}_{11} \mathrm{Cl}_{4}$. The indexed data are summarized in table 3 .

Table 3. Cell parameters and indexed lines for the X-ray diffraction pattern for $\mathrm{Co}_{2} \mathrm{Cu}_{4} \mathrm{Te}_{4} \mathrm{O}_{11} \mathrm{Cl}_{4}$.

\begin{tabular}{|c|c|c|c|c|c|c|}
\hline Cell Parameters & a & b & c & $\alpha$ & $\beta$ & $\gamma$ \\
\hline $\mathrm{Ba}_{2} \mathrm{Cu}_{4} \mathrm{Te}_{4} \mathrm{O}_{11} \mathrm{Cl}_{4}{ }^{27}$ & 9.275 & 12.135 & 9.260 & 98.23 & 108.35 & 110.90 \\
\hline $\begin{array}{c}\mathrm{Co}_{2} \mathrm{Cu}_{4} \mathrm{Te}_{4} \mathrm{O}_{11} \mathrm{Cl}_{4} \\
{[\text { this work] }}\end{array}$ & 9.274 & 12.132 & 9.252 & 98.18 & 108.22 & 111.07 \\
\hline
\end{tabular}

\begin{tabular}{|rrr|c|c|c|}
\hline H & K & L & 2Th(obs) & 2Th(Calc) & diff. \\
\hline & & & & & \\
\hline 1 & -2 & 1 & 18.5400 & 18.4359 & 0.1041 \\
\hline-1 & 0 & 2 & 19.5700 & 19.5951 & -0.0251 \\
\hline-2 & 1 & 1 & 19.6400 & 19.5838 & 0.0562 \\
\hline-2 & 1 & 1 & 19.7100 & 19.5838 & 0.1262 \\
\hline-2 & 0 & 1 & 20.4700 & 20.5995 & -0.1295 \\
\hline 0 & -2 & 2 & 22.6700 & 22.7196 & -0.0496 \\
\hline 0 & -2 & 2 & 22.7500 & 22.7196 & 0.0304 \\
\hline 2 & -3 & 1 & 27.9000 & 28.0356 & -0.1356 \\
\hline 1 & 2 & 1 & 29.4100 & 29.3810 & 0.0290 \\
\hline 0 & -1 & 3 & 30.5000 & 30.5287 & -0.0287 \\
\hline-1 & -3 & 2 & 30.6200 & 30.6280 & -0.0080 \\
\hline-3 & 2 & 2 & 31.9500 & 31.9580 & -0.0080 \\
\hline-3 & 0 & 2 & 32.0300 & 32.0311 & -0.0011 \\
\hline 1 & -4 & 2 & 33.6200 & 33.7304 & -0.1104 \\
\hline 0 & -3 & 3 & 34.3200 & 34.3695 & -0.0495 \\
\hline 0 & -3 & 3 & 34.4000 & 34.3695 & 0.0305 \\
\hline 3 & -2 & 1 & 35.1600 & 35.1328 & 0.0272 \\
\hline-2 & 5 & 0 & 37.8100 & 37.7608 & 0.0492 \\
\hline-1 & 0 & 4 & 39.7100 & 39.7574 & -0.0474 \\
\hline 2 & 3 & 0 & 40.3300 & 40.2839 & 0.0461 \\
\hline
\end{tabular}




\begin{tabular}{|c|c|c|c|}
\hline $\begin{array}{ll}-1 & 5 \\
\end{array}$ & 41.7200 & 41.6256 & 0.0944 \\
\hline $\begin{array}{ll}0 & -3\end{array}$ & 43.1900 & 43.0762 & 0.1138 \\
\hline-15 & 47.5900 & 47.6436 & -0.0536 \\
\hline-36 & 48.6400 & 48.6644 & -0.0244 \\
\hline$-4 \quad-1$ & 50.0500 & 50.0578 & -0.0078 \\
\hline-26 & 52.9800 & 52.9805 & -0.0005 \\
\hline 12 & 57.7900 & 57.7979 & -0.0079 \\
\hline 24 & 60.9200 & 60.9543 & -0.0343 \\
\hline $2 \quad-3$ & 74.4800 & 74.4553 & 0.0247 \\
\hline \multicolumn{4}{|c|}{$\begin{array}{ll}\operatorname{Sqrt}(\operatorname{Sum}(2 \mathrm{Th} O-C) * * 2) /(\text { Nref-Npar })) & : 0.0726 \\
\operatorname{Sart}(\operatorname{Sum}(2 \mathrm{Th} \text { O-C }) * * 2) / \text { Nref }) & : 0.0647\end{array}$} \\
\hline
\end{tabular}

Recently Kolis et. al ${ }^{27}$ synthesized two new phases $\mathrm{Ba}_{2} \mathrm{Cu}_{4} \mathrm{Te}_{4} \mathrm{O}_{11} \mathrm{Cl}_{4}$ and $\mathrm{BaCu}_{2} \mathrm{Te}_{2} \mathrm{O}_{6} \mathrm{Cl}_{2}$, and were able to reach the interesting structural properties of the telurites with the physical properties of the oxychlorides. These phases correspond to lamellar telurites of copper and barium, with the incorporation of chloride as mineralizing agent. In this way it is possible to obtain oxychlorides of these phases, where it is possible to find unusual square planar coordinations due to the presence of tellurium( IV ) oxoanions. From the structural point of view, in the $\mathrm{Ba}_{2} \mathrm{Cu}_{4} \mathrm{Te}_{4} \mathrm{O}_{11} \mathrm{Cl}_{4}$ phase $\mathrm{Cu}$ (I) atoms co-exist in tetrahedral or trigonal planar configurations and the $\mathrm{Cu}$ (II) atoms are in the square planar configuration, separated by chloride and oxide layers respectively. Barium atoms are located in the interlamellar space ( Figure 3 ).

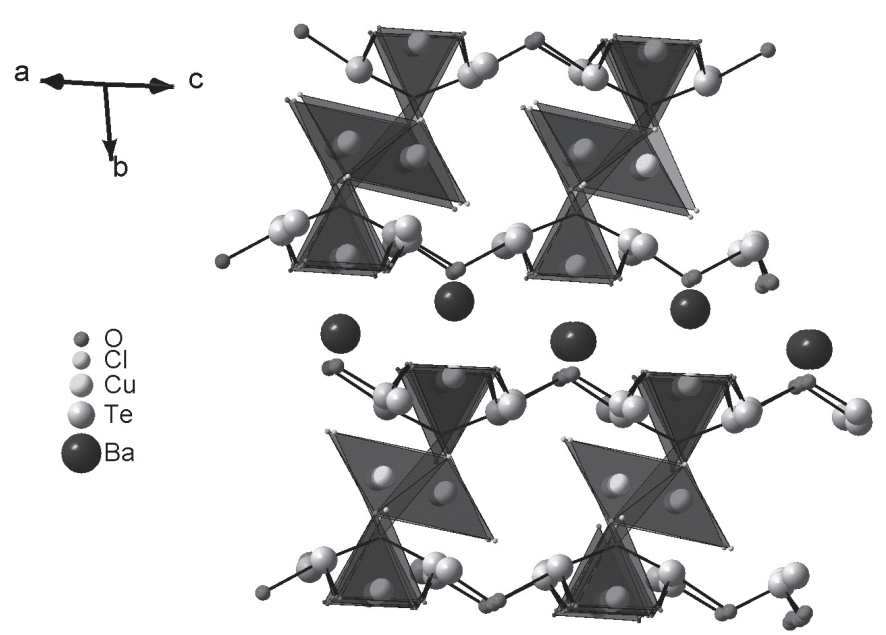

Figure 3. Crystalline structure of the $\mathrm{Ba}_{2} \mathrm{Cu}_{4} \mathrm{Te}_{4} \mathrm{O}_{11} \mathrm{Cl}_{4}$ phase

It is interesting to remark that the ionic radii of $\mathrm{Co}(\mathrm{II})$ and $\mathrm{Ba}(\mathrm{II})$ are 0.78 and $1.35 \AA$ respectively. However, both oxychloride phases which contain these divalent cations are isoestructural. This can be explained by the fact that these ions must have a weak influence on the interlamellar space, and consequently on the lattice parameters.

Diffuse reflectance spectroscopy was used to determine the optical band gap of the obtained compound. A plot of absorbance $\mathrm{v} / \mathrm{s}$ energy for $\mathrm{Co}_{2} \mathrm{Cu}_{4} \mathrm{Te}_{4} \mathrm{O}_{11} \mathrm{Cl}$ is shown in Figure 4. The band gap was obtained by determining the inflection point of the first derivative curve of reflectance $\mathrm{v} / \mathrm{s}$ energy. The obtained band gap was $2.7 \mathrm{eV}$, indicative of an essentially insulating material, and can be compared with previous data reported for $\mathrm{Ba}_{2} \mathrm{Cu}_{4} \mathrm{Te}_{4} \mathrm{O}_{11} \mathrm{Cl}_{4}(3.0 \mathrm{eV})$. Thus a less insulating behavior is observed for the studied $\mathrm{Co}$ (II) phase.

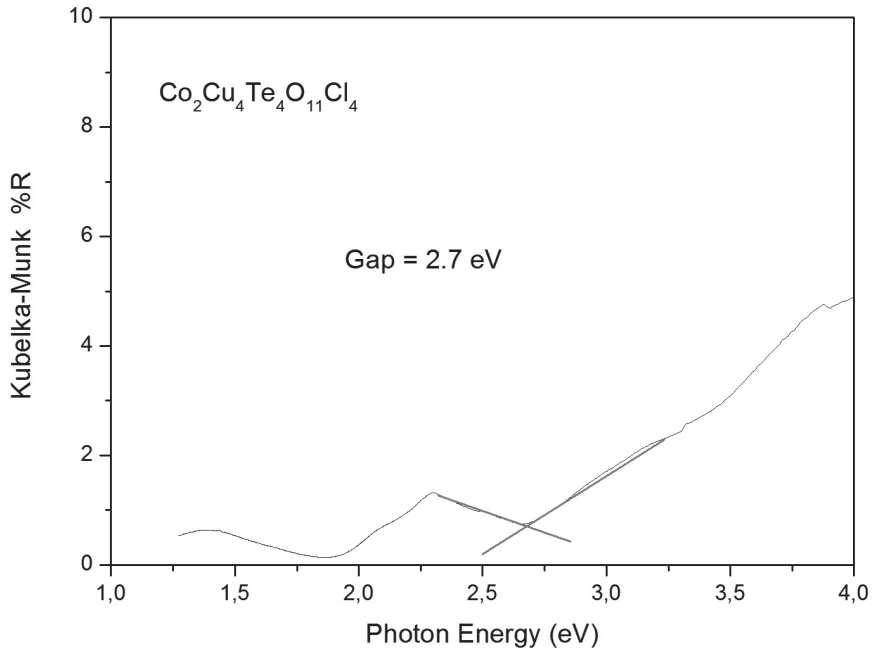

Figure 4. Plot of the diffuse reflectance spectrum of $\mathrm{Co}_{2} \mathrm{Cu}_{4} \mathrm{Te}_{4} \mathrm{O}_{11} \mathrm{Cl}_{4}$

Thermogravimetric data were obtained between room temperature and $800{ }^{\circ} \mathrm{C}$, showing that the phase is stable in air to $700^{\circ} \mathrm{C}$ with a loose of weight of $11 \%$ associated to a decomposition process ( Figure 5 ).

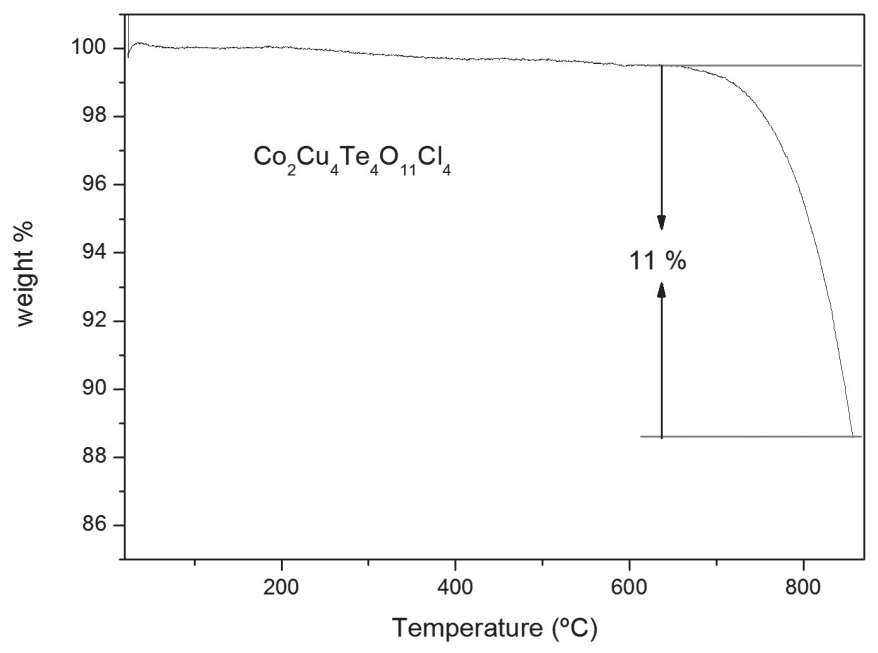

Figure 5. TG curve for $\mathrm{Co}_{2} \mathrm{Cu}_{4} \mathrm{Te}_{4} \mathrm{O}_{11} \mathrm{Cl}_{4}$

\section{CONCLUSION}

After several attempts we were able to obtain the exact experimental conditions to prepare the $\mathrm{Co}_{2} \mathrm{Cu}_{4} \mathrm{Te}_{4} \mathrm{O}_{11} \mathrm{Cl}_{4}$ phase.

It is clear that the variation in the ratios of the solid reagents and the mineralizer, promotes in most cases the formation of the spiroffite structure like the most stable compound, and a detailed control of the experimental conditions is needed.

\section{ACKNOWLEDGMENTS}

The authors acknowledge the financial support of FONDECYT GRANT 3060073 and FONDAP GRANT 11980002. The authors thank Prof. A. West for the diffraction facilities at the University of Sheffield, UK and Prof. J. Llanos for diffuse reflectance measurements and thermogravimetric analyses. 


\section{REFERENCES}

1.- Shouhua Feng and Ruren Xu. Acc. Chem. Res. 34 (3), 239 (2001).

2.- Cheetham, A. K.; Ferey, G.; Loiseau, T. Angew. Chem., Int. Ed. Engl. 38, 3268 (1999).

3.- Li, G.; Li, L.; Feng, S.; Wang, M.; Yao, X. Adv. Mater. 11 (2), 146 (1999).

4.- Feng, S.; Greenblatt, M. Chem. Mater. 4 (6), 1257 (1992).

5.- Chen, Q. W.; Qian, Y. T.; Chen, Z. Y.; Tang, K. B.; Zhou, G. E.; Zhang, Y. H. Physica C, 224 (3-4), 228 (1994).

6.- Feng, S.; Wang, D.; Yu, R.; Na, L. Hydrothermal Synthesis Route to a Giant Magnetoresistance Material $\mathrm{La}_{05} \mathrm{Ba}_{05} \mathrm{MnO}_{3}$, Proceedings of the International Symposium on Solvo-Hydro-Thermal Processes; Org. Comm. Solvothermal Tech. Res.: Takamatsu, Japan,; p12 (1997).

7.- Rouxel, J.; Palvadeau, P.; Venien, J. P.; Villieras, J.; Janvier, P.; Bujoli, B. Mater. Res. Bull. 22, 1217 (1987).

8.- Song, K.; Kauzlarich, S. M. Chem. Mater. 6, 386 (1994).

9.- Kargina, I.; Richeson, D. Chem. Mater. 8, 480 (1996).

10.- Uitert Van, L. G.; Singh, S.; Levinsein, H. J.; Johnson, L. F.; Grodkiewicz, W. H.; Geusic, J. E. Appl. Phys. Lett. 15, 53(1969).

11.- Holsa, J.; Lamminmaki, R.-J.; Antic-Fidancev, E.; Lemaitre-Blaise, M.; Porcher, P. J. Phys.: Condens. Matter, 7, 5127 (1995).

12.- Berdonosov, P. S.; Stefanovitch, S. Y.; Dolgikh, V. A. J. Solid State Chem. 149, 236 (2000).

13.- Ackerman, J. F. J. Solid State Chem. 62, 92 (1986).
14.- Hiroi, Z.; Kobayashi, N.; Takano, M. Nature, 371, 139 (1994).

15.- Jin, C.-Q.; Wu, X.-J.; Laffez, P.; Tatsuki, T.; Tamura, T.; Adachi, S.; Yamauchi, H.; Koshizuka, N.; Tanaka, S. Nature, 375, 301 (1995)

16.- K. Yamaura, D. P. Young, T. Siegrist, C. Besnard, C. Svensson, Y. Liu and R. J. Cava.

J. Solid State Chem. 158, 175 (2001).

17.- Knee, C. S.; Zhukov, A. A.; Weller, M. T. Chem. Mater. 14 (10), 4249 (2002).

18.- Kusainova, A. M.; Lightfoot, P.; Zhou, W.; Stefanovich, S. Yu.; Mosunov, A. V.; Dolgikh, V. A. Chem. Mater. 13 (12), 4731 (2001).

19.- K. Okamoto, N. Imanaka and G. Adachi. Solid State Ionics. 154-155, 577 (2002).

20.- Cava, R. J.; Bordet, P.; Capponi, J. J.; Chaillout, C.; Chenavas, J.; Fournier, T.; Hewat, E. A.; Hodeau, J. L.; Levy, J. P.; Marezio, M.; Batlogg, B.; Rupp, L. W. Physica C, 167, 67 (1990).

21.- Tatsuki, T.; Tamura, T.; Moriwaki, Y.; Wu, X.-J.; Adachi, S.; Tanabe, K. Physica C, 270, 327 (1996)

22.- Feger, C. R.; Kolis, J. W. Inorg. Chem. 37, 4046 (1998).

23.- Hanke, K. Naturwissenschaften, 54, 199 (1967).

24.- Hanke, K. Naturwissenschaften, 53, 273 (1966).

25.- Hanke, K.; Kupcik, V.; Lindqvist, O. Acta Crystallogr. B29, 963 (1973).

26.- Christopher R. Feger, George L. Schimek and Joseph W. Kolis. J. Solid State Chem. 143, 246 (1999).

27.- Christopher R. Feger and Joseph W. Kolis. Inorg. Chem. 37 (16), 4046 (1998). 